Cadernos de Clio, Curitiba, v. 6, nº 1, 2015

\title{
CALVEIRO, Pilar. Poder e desaparecimento: os campos de concentração na Argentina. tradução Fernando Correa Prado. São Paulo: Boitempo, 2013, $151 \mathrm{p}$.
}

Michel Ehrlich ${ }^{1}$

Pilar Calveiro nasceu na Argentina em 1953. Envolvida em militâncias sociais e políticas, foi presa pela ditadura civil-militar que governou o país no período de 1976 a 1983. No prelúdio do livro, o poeta Juan Gelman, descreve:

"Em 7 de maio de 1977, um comando da Aeronáutica sequestrou
Pilar Calveiro em plena rua e a levou ao que ficou conhecido
como "Mansão Seré" [...]Naquele dia começou seu percurso de
um ano e meio num inferno que continuou em outros campos de
concentração" (p.19)

Ao contrário da enorme maioria dos detidos em campos de concentração argentinos (cerca de $90 \%$ dos 15 a 20 mil pessoas que por isso passaram, segundo a própria autora), Pilar Calveiro sobrevive. Mais tarde, realiza doutorado em ciência política pela Universidade Nacional do México, parte da qual resulta nesse livro, lançado na Argentina em 2001. Atualmente, é professora e pesquisadora na Universidade Autônoma de Puebla (México).

Apesar dessa vivência, Calveiro não baseia seu livro unicamente no seu depoimento. Suas principais fontes são o testemunho de cinco

\footnotetext{
${ }^{1}$ Estudante de graduação em História (bacharelado e licenciatura) pela Universidade Federal do Paraná (UFPR).
} 
outros sobreviventes. De acordo com ela

"Cada depoimento é um universo completo, um homem completo
falando de si e dos outros. Seria suficiente tomar apenas um deles
para abarcar os fenômenos aos quais quero me referir. Ainda as-
sim, para mostrar a vivência a partir de diferentes sexos, sensibi-
lidades, militâncias, lugares geográficos e capturadores, e mesmo
fazendo referência a outros depoimentos, tomarei basicamente os
seguintes: Graciela Geuna (sequestrada no campo de concentra-
ção de La Perla, Córdoba, correspondente ao III Corpo do Exér-
cito), Martín Gras (sequestrado na Esma, Capital Federal, corres-
pondente à Marinha da República Argentina), Juan Carlos Scar-
patti (sequestrado e foragido de Campo de Mayo, província de
Buenos Airese, campo de concentração correspondente ao I Cor-
po do Exército), Claudio Tamburrini (sequestrado e foragido da
Mansão Seré, província de Buenos Aires, correspondente à Força
Aérea) e Ana María Careaga (sequestrada em El Atlético, Capital
Federal, correspondente à Polícia Federal)". (p.42)

O livro de Pilar Calveiro não se resume, contudo, à transmissão desses testemunhos, mas à, a partir deles, refletir sobre os desaparecimentos na ditadura argentina e sobre o fenômeno repressivo em si. Retomando o prelúdio de Gelman "este livro é uma façanha. Pilar Calveiro atravessou a situação mais extrema do horror e teve a difícil capacidade de pensar a experiência" (p.20). Ao fazê-lo, "Sua leitura contribui para a reflexão sobre a história não só da Argentina, mas dos outros países do Cone Sul, que não pode ser relegada ao esquecimento", escreve a historiadora da USP Maria Helena Capelato, na orelha do livro.

A edição brasileira do livro tem apresentação da pesquisadora de pós-doutorado em História Social da USP Janaína de Almeida Teles intitulada "Ditadura e repressão no Brasil e na Argentina: paralelos e distinções". Nesta, aponta algumas semelhanças e diferenças entre os 
processos ocorridos nos dois países. Se em ambos os casos havia uma noção de que os militares estariam salvando o país de uma ameaça inimiga, o "poder desaparecedor" descrito por Calveiro para a Argentina seria no Brasil mais um "poder torturador". Em alguns casos, em especial no combate a guerrilha do Araguaia, a ditadura brasileira também usou a tática de eliminação total do "inimigo". Porém, em geral, se caracterizava por "seu caráter centralizado e seletivo, permeado por preocupações com sua legitimidade institucional" (p. 14). Assim, no Brasil, o governo se preocupava em dar um ar de legitimação legal, mesmo que manipulada, às suas ações, enquanto na Argentina estava mais cristalizada a ideia de que diante de um inimigo tão perigoso, métodos excepcionais poderiam ser utilizados. Portanto, na Argentina

\begin{abstract}
"o eixo do mecanismo desaparecedor era a obtenção de informação necessária para multiplicar os desaparecimentos até acabar com o "inimigo"'. No modelo brasileiro, por sua vez, o foco era a seletividade e a obtenção de informações para desestruturar grupos oposicionistas." (p. 17)
\end{abstract}

Pilar Calveiro divide o livro em duas partes. A primeira, mais curta, "Considerações Preliminares", fornece um panorama do contexto prévio ao golpe que levou o general Jorge Videla ao governo em 1976. A segunda parte, "Os campos de concentração" descreve e discute o funcionamento, a lógica e o significado dos campos de concentração argentinos.

"Considerações Preliminares" apresenta primeiramente a ascensão das forças armadas, e depois a situação das guerrilhas, vistas pela ditadura como o principal inimigo interno. Desde a década de 1930, as 
forças armadas cresciam em peso político e autonomia.

"Assim, ao longo de 45 anos os militares reiteradamente "salvaram" o país - ou melhor, os grupos dominantes do país. Por outro lado, setores importantes da sociedade civil também reclamaram e exigiram essa salvação. Em 1976, não havia nenhum partido político na Argentina que não tivesse apoiado algum dos numerosos golpes militares ou dele participado." (p 25)

Assim, o apelo às forças armadas ao reestabelecimento da ordem (e as características fundamentais de um governo militarizado) não era inédito na Argentina de 1976, quando a crise do peronismo fazia em especial as classes médias clamarem por serem "salvas".

As guerrilhas, cujos membros formariam grande parte da população sequestrada proliferaram nos anos 1970, sejam de caráter guevarista ou peronista. Calveiro, porém, tece críticas ao autoritarismo interno a elas, o que teria colaborado, junto à repressão por parte do peronismo de direita a partir de 1974, para que já estivessem bastante enfraquecidas em 1976.

A segunda e mais extensa parte do livro inicia-se com uma ideia fundamental do texto: "Sempre o poder mostra e esconde, e se revela tanto no que exibe quanto no que oculta" (p. 38). Portanto, os mecanismos de desaparecimentos deviam ser escondidos (já que não eram legais), mas somente parcialmente. Para Calveiro, "para disseminar o terror, cujo efeito imediato é o silêncio e a inação, é preciso mostrar uma fração daquilo que permanece oculto”. (p. 53). A autora então esclarece que o sequestro, a tortura e o desaparecimento já eram prática corrente ao menos desde 1966, mas a partir de 1976, o desaparecimento 
deixa de ser uma das formas para se tornar a própria definição da repressão na ditadura argentina.

Uma característica importante é que os campos de concentração não eram operados por um grupo seleto. Pelo contrário, havia um esforço em incluir grande número de oficiais, de modo a implicar a todos no processo, em cumplicidade geral. O resultado disso era, além de evitar delações, que seres humanos sem "natureza assassina" participassem ativamente de "um maquinário, construído por eles mesmos, cujo mecanismo os levou a uma dinâmica de burocratização, rotineirização e naturalização da morte" (p. 45). O relato de Calveiro nos remete, ao conceito de banalidade do mal, desenvolvido por Hannah Arendt em Eichmann em Jerusalém, autora com cuja obra o livro de Pilar Calveiro está em constante diálogo.

Nas páginas seguintes, Calveiro descreve os procedimentos do desaparecimento. A iniciar pelo sequestro, realizado por grupos que geralmente desconheciam o motivo da operação e a tortura (choques elétricos e abusos sexuais eram comuns). Cabe salientar que a missão principal da tortura (que começava antes mesmo da inserção do prisioneiro no campo) era "“"alimentar" o campo com novos sequestrados" (p. 67). Seguidas as primeiras seções de tortura, ocorria o confinamento no campo (novamente, os guardas geralmente não sabiam quem eram os prisioneiros, somente sabiam que eram "perigosos"), período no qual podiam ocorrer novas torturas, e finalmente o assassinato e desaparecimento dos corpos. Esta é a parte menos conhecida. Um dos métodos envolvia a aplicação de soníferos e o despejo dos corpos (ainda vivos) 
no mar. Ao longo de todo o processo, imperava a burocracia, a impessoalidade e a divisão de tarefas. Em Modernidade e Holocausto, Zygmunt Bauman afirma que

\begin{abstract}
"O uso da violência é mais eficiente e menos dispendioso quando os meios são submetidos a critérios instrumentais e racionais e, assim dissociados da avaliação moral dos fins. [...] A dissociação é, de modo geral, resultado de dois processos paralelos, ambos centrais ao modelo burocrático de ação. O primeiro é a meticulosa divisão funcional do trabalho [...] o segundo é a substituição da responsabilidade moral pela técnica." (BAUMAN, 1998, p. 122)
\end{abstract}

Atenta a essas semelhanças, Calveiro afirma que isso não se deveria a uma cópia ou inspiração nos campos nazistas ou stalinistas mas consequência de serem poderes totalizantes.

Outra característica apontada pela autora que reforça esse caráter totalizante é a auto-representação de muitos torturadores como deuses, ao ponto de impedirem o suicídio mesmo de prisioneiros cujo destino (morte) já estava selado. Havia uma necessidade de reafirmar o poder da repressão sobre cada mínimo aspecto da vida (e da morte) dos sequestrados.

$\mathrm{O}$ aspecto fragmentário do processo, com diferentes grupos operativos trabalhando em paralelo e até concorrendo entre si causava uma sensação de completa ausência de lógica (por exemplo, na escolha de quem iria morrer e quando) e desarmava tentativas de resistência. No entanto, "O fragmentário não se opõe ao totalizante; pelo contrário, eles se combinam e se sobrepõe, sem encontrar nenhuma consistência ou coerência." (p. 82). Tal afirmação é reforçada por Hannah Arendt, 
quando afirma, sobre a burocracia nazista que "todos esses organismos, enormemente poderosos, competiam ferozmente uns com os outros - o que em nada ajudava suas vítimas" (ARENDT, 1999, p. 85).

Analisado o funcionamento concreto do "poder desaparecedor", Pilar Calveiro se dedica ao componente ideológico que o sustenta, ao qual chama de "Um universo binário".

"As lógicas totalitárias são lógicas binárias, que concebem o
mundo como dois grandes campos contrários: o próprio e o
alheio. [...] entende que o diferente constitui um perigo iminente
ou latente, que deve ser extirpado. [..,] pretende, em última ins-
tância, eliminar as diversidades e impor uma realidade única e
total representada pelo núcleo duro do poder, o Estado." (p. 88)
"Na concepção militar, a Argentina estava em guerra: uma guerra
contra a subversão, travada dentro e fora das fronteiras nacionais.
Os militares se apressaram a declará-la, e a guerrilha aceitou o
desafio." (p, 89)

Assim, na ótica militar, não desapareciam pessoas, mas sim subversivos, que seriam sempre: guerrilheiros, servindo interesses estrangeiros, perigosos, imorais; se mulheres, cruéis e sem moral sexual. No caso dos mais perigosos não só sem religião, mas judeus. "Reduzidos, como todos os outros objetos de gerenciamento burocrático, a meros números desprovidos de qualidade, os objetos humanos perdem sua identidade.”(BAUMAN, 1998, p. 127)

Portanto, os campos de concentração procuravam retirar por completo a humanidade do prisioneiro. Calveiro, porém, defende que "apesar da eficiência da técnica concentratória, quase sempre há uma parte do homem que é devastada e outras que resistem; essas são as partículas que escapam” (p. 102). Isso permite problematizar o universo 
binário e mais, possibilita formas de resistência e fuga. Em relação a esses mecanismos, Calveiro afirma que

"É preciso acrescentar que existiram diversas formas de fugir do dispositivo concentracionário, não apenas a fuga física, sendo que todas elas estiveram associadas à preservação da dignidade, à ruptura da disciplina e à transgressão da normatividade, sabotando os objetivos do campo.” (p. 108)

Assim, a autora descreve várias formas de fuga e resistência, desde a fuga concreta, a colaboração falsa ou parcial, a solidariedade interna, até o riso como reafirmação da vida.

Aproximando-se da parte final do livro, Calveiro reafirma, tal como Hannah Arendt teve que fazer no caso Eichmann, que "Ao encarar os desaparecedores como parte do cotidiano social, sua responsabilidade não se esfuma; apenas os situa num lugar que envolve e questiona toda a sociedade." (p.134). Arendt completaria que "essa normalidade era muito mais apavorante do que todas as atrocidades juntas" (ARENDT, 1999, p. 299).

Essa reflexão faz com que a análise não possa se prender somente aos que participaram diretamente nos desaparecimentos, devendo se estender a sociedade toda: "O campo de concentração, [...], só pode existir numa sociedade que escolhe não ver, por sua própria impotência; uma sociedade "desaparecida", tão siderada como os próprios sequestrados." (p. 135). Calveiro descreve como o golpe teve respaldo social. "Se havia algo que não tinha como ser alegado naquele momento era o desconhecimento" (p. 136). A tortura, os sequestros e a necessidade de eliminação do Outro não eram novidade e já estavam até certo ponto 
naturalizadas. "A noção do Outro, perigoso, que deve ser destruído, estava profundamente enraizada nas representações e práticas políticas." (p. 138).

Poder e desaparecimento, portanto, está muito distante de ser somente um testemunho da ditadura (o que já seria válido). Tampouco se limita a uma análise do "poder desaparecedor" na Argentina no período 1976-1983, o que realiza brilhantemente. Pilar Calveiro é capaz, apesar ou talvez justamente por ter sido vítima da repressão autoritária de analisar, a partir da experiência argentina, o fenômeno do autoritarismo totalizante, o que, levando em conta seus paralelos e particularidades, colabora para a compreensão das ditaduras civis-militares que assolaram o Cone Sul nas décadas de 1960,70 e 80.

Ao final do livro, Calveiro afirma:

\begin{abstract}
"a melhor forma para desconhecer que a realidade dos campos de concentração esteve estreitamente relacionada com a sociedade de então e com a atual é esquecê-los, decidir que o mundo e o país deram voltas suficientes a ponto de chegar a outro lugar. Anistia, como amnésia, vem de a-mnses-is, "esquecimento"” (p. 151).
\end{abstract}

A mensagem não poderia ser mais evidente para um Brasil que ainda se debate em relação à memória e aos aspectos ainda hoje remanescentes da sua ditadura mais recente.

\title{
Referências bibliográfias
}

ARENDT, Hannah. Eichmann em Jerusalém: um relato sobre a banalidade do mal. Tradução José Rubens Siqueira. São Paulo: Companhia das Letras, 1999. 
Cadernos de Clio, Curitiba, v. 6, $\mathrm{n}^{\circ}$ 1, 2015

BAUMAN, Zygmunt. Modernidade e Holocausto. Tradução Marcus Penchel. Rio de Janeiro: Zahar, 1998.

CALVEIRO, Pilar. Poder e desaparecimento: os campos de concentração na Argentina. Tradução Fernando Correa Prado. São Paulo: Boitempo, 2013.

Recebido em: 01/06/2015

Aceito em: 20/08/2015 